\title{
Early Outcomes after Total Correction for Tetralogy of Fallot Patients at Department of Cardiothoracic and Vascular Surgery Amiri Medical Complex Kabul-Afghanistan (A Single Center Study)
}

\author{
Manochihr Timorian ${ }^{1,2, *}$, Razmi Rahman ${ }^{3}$ and Abdul Saboor Saboor ${ }^{4}$ \\ ${ }^{1}$ Department of Cardiothoracic and vascular Surgery, Global Medical Complex, Afghanistan \\ ${ }^{2}$ Department of Cardiothoracic and Vascular Surgery, Amiri Medical Complex, Afghanistan \\ ${ }^{3}$ Department of Pediatric Cardiology, Amiri Medical Complex, Afghanistan \\ ${ }^{4}$ Department of Pulmonology and Critical Care, Amiri Medical Complex, Afghanistan
}

Received: 12 May, 2019 | Accepted: 24 Jun, 2019 | Published: 01 Jul, 2019

${ }^{*}$ Corresponding author: Manochihr Timorian, Department of Cardiothoracic and vascular Surgery, Global Medical Complex, Afghanistan, E-mail: manochihr@yahoo.com

Citation: Timorian M, Rahman R, Saboor AS (2019) Early Outcomes after Total Correction for Tetralogy of Fallot Patients at Department of Cardiothoracic and Vascular Surgery Amiri Medical Complex Kabul-Afghanistan (A Single Center Study). Clin Res Open Access 5(1): dx.doi. org/10.16966/2469-6714.146

Copyright: ( 2019 Timorian M, et al. This is an open-access article distributed under the terms of the Creative Commons Attribution License, which permits unrestricted use, distribution, and reproduction in any medium, provided the original author and source are credited.

\begin{abstract}
Tetralogy of Fallot is the most common cyanotic congenital heart disease. The first complete repair of tetralogy of Fallot was successfully performed by C. Walton Lillehi and his team in 1954, but first total correction performed at department of cardiothoracic and vascular surgery Amiri Medical Complex Kabul Afghanistan in 2015, despite some advocates of routine two-stage repair in infancy, during the early 1990s reports documented improve early results with primary repair was associated with improved outcome compared to a two-stage approach. The purpose of this study was to analyze the early postoperative result in total correction for the first time in Afghanistan.
\end{abstract}

Method: The purpose of this study was to evaluate the early outcome after total correction in 180 consecutive patients with a mean age of 5-30 years who underwent total correction surgery in a single center Amiri Medical Complex, Kabul, Afghanistan between August 2015 and October 2018. 8 patients had initial palliative operations (modified BT shunt) in outside centers and referred to us for total correction. The trans annular pericardial patch was inserted in $133(73.8 \%)$ patients. $32(17.7 \%)$ patients repaired by trans atrial total correction (ventricular septal defect, right ventricular outflow tract muscle band resection and pulmonary valvotomy done through the right atrium ) for $5(2.7 \%)$ patients with absent pulmonary valve, monocuspid and bicuspid pulmonary valve reconstructed with a pericardial patch.

Result: Mean follow up was (1-3) months postoperatively, the mortality rate was (8.8\%). Most of the patients who repaired with trans annular patch had free pulmonary valve regurgitation post-operative period by transthoracic echocardiography 26 patients had the excellent function of their native repaired pulmonary valve and monocusp, bicuspid reconstructed pulmonary valve. The peak gradient of right ventricular outflow tract was between 10 to $35 \mathrm{mmHg}$ postoperatively. 22 patients had small (tiny) residual ventricular septal defect and none of the patients had complete heart block (0\%).

Conclusion: Total correction for tetralogy of Fallot patients may have low operative mortality and provide excellent short and long term survival in modern centers; this experience suggests that total correction for tetralogy of Fallot patients would have good short term outcomes in developed countries.

Keywords: Congenital heart surgery; Cyanotic heart disease; Tetralogy of fallot

\section{Introduction}

The first complete repair of tetralogy of Fallot was successfully performed by C. Walton Lillehi and his team in 1954 [1-5]. The purpose of this study was to analyze early postoperative and early result in total correction of tetralogy of fallot at the department of cardiothoracic surgery Amiri medical complex for the first time in Afghanistan.

\section{Patients and Methods}

\section{Patients}

Between August 2015 to September 2018, 180 consecutive patients with Tetralogy of Fallot (TOF) (pink TOF Spo $2>80 \%$ in room air and blue TOF Spo $2<80 \%$ in room air) underwent total correction for Tetralogy of Fallot at department of cardiothoracic and vascular 
surgery Amiri medical complex Kabul Afghanistan for the first time, there were 101(56.1\%) male patient and $79(43.8 \%)$ were female patients with age of 5 to 30 years and weight was $(9-55 \mathrm{~kg})$.

This includes a patient with classic tetralogy of Fallot and associated pathologic processes such as atrial septal defect, patent ductus arteriosus and absent pulmonary valve, etc. (Table 1). There were just $8(4.4 \%)$ patients with primary palliative procedures (modified BT shunt) were referred to us for total correction from outside centers. The diagnosis of tetralogy of Fallot for all patients was made by transthoracic echocardiography, CT angiography and cardiac catheterizations (Table 2) [6].

\section{Data collection}

From a review of the medical record, the follow up was achieved in $156(86.6 \%)$ patients in the cardiology clinic, mean follow up was 30-90 days post-operative.

\section{Operative procedure}

The heart exposed through a median sternotomy a patch of the pericardium was removed for ventricular septal defect repair and right ventricular outflow tract reconstruction, pulmonary artery trunk with branches dissected.

The operation was performed under cardiopulmonary bypass with mild hypothermia (nasopharyngeal temperature of 30-32c) intermittent doses of cold cardioplegia (del Nido cardioplegia) were used for myocardial protection, right atriotomy was used to expose the ventricular septal defect and right ventricular outflow tract muscle band resection.

In trans right atrium total correction, ventricular septal defect, right ventricular outflow tract muscle band resection and pulmonary valve commissurotomy were done through the right atrium [7]. Ventricular septal defect patch was sewn by continues suture [8], the right ventricular outflow tract and pulmonary artery were enlarged with autologous pericardium in [9] 133(73.8\%) patients, monocuspid and bicuspid pulmonary valve reconstructed with autologous pericardium in $15(8.3 \%)$ patients. In case of right or left pulmonary artery stenosis the patch was carried beyond the point of stenosis, all patent foramen oval was closed by direct sutures and atrial septal defects were closed by pericardial patches.

Table 1: Associated Cardiopulmonary Abnormalities.

\begin{tabular}{|l|c|c|}
\hline \multicolumn{1}{|c|}{ Variable } & Numbers & Percentage \\
\hline No associated abnormalities & 88 & $48.8 \%$ \\
\hline Patent Ductus Arteriosus (PDA) & 12 & $6.6 \%$ \\
\hline Patent Foramen Oval (PFO) & 25 & $13.8 \%$ \\
\hline Left Superior Vena Cava (LSVC) & 18 & $10 \%$ \\
\hline Atrial Septal Defect (ASD) & 23 & $12.7 \%$ \\
\hline Major Aortopulmonary Collaterals (MAPCA'S) & 9 & $5 \%$ \\
\hline Absent pulmonary valve & 5 & $2.7 \%$ \\
\hline
\end{tabular}

Table 2: Major Diagnostic Tools for the Diagnosis of Tetralogy of Fallot.

\begin{tabular}{|l|c|c|}
\hline \multicolumn{1}{|c|}{ Procedure } & Number & Percentage \\
\hline Transthoracic echocardiography & 180 & $100 \%$ \\
\hline Pulmonary CT angiography & 23 & $12.7 \%$ \\
\hline Cardiac catheterization & 12 & $6.6 \%$ \\
\hline
\end{tabular}

\section{Results \\ Early result}

Overall mortality rate was (8.8\%) 16 patients, 4 patients died due to severe bleeding (pulmonary hemorrhage, 2 patients because of right ventricular failure, 3 patients died due to multi-organ failure, 4 patients because of sepsis, in 3 patients ventricular septal defect patch dehiscence occurred and they died because of heart failure (patients attendant were not agreed with reoperation) there was not on table death.

Aortic cross-clamp time was $(30-45 \mathrm{~min})$ and cardiopulmonary bypass time was (55-75min), factors affecting operative survival were analyzed, aortic cross-clamp time and cardiopulmonary bypass time not affected operative survival.

The previous palliative procedure did not adversely affect operative mortality.

Among operative measurement construction of the right ventricular outflow tract with a patch was not related to early mortality [10], perioperative measurement of hematocrits level was significantly related to early mortality and perioperative thrombocytopenia was the great risk factor for postoperative mortality $[11,12]$.

Postoperative ventilation more than 48 hours than tracheostomy was necessary for 3(1.6\%) patients, transient right heart failure required inotropic support for 72 hours occurred in $18(10 \%)$ patients, use of temporary pacemaker was required in $13(7.2 \%)$ patients, no patient required permanent pacemaker implantation in the perioperative period, postoperative complication shown in (Table 3 ).

The median length of stay in the intensive care unit was 2-8 days, the median hospital stay was 4-16 days.

Residual anatomical defect was first diagnosed by clinical and echocardiographic or both, 22 patients had a tiny residual Ventricular Septal Defect (VSD) and most of the patients with trans annular patch had free pulmonary valve regurgitation, 5(2.7\%) patients with pulmonary valve reconstruction (bicusp and monocusp pulmonary valve) with pericardial patch had good function of reconstructed valve with mild pulmonary valve regurgitation, $32(17.7 \%)$ patients who repaired trans right atrium total correction had excellent function of pulmonary valve and right ventricle function.

\section{Discussion}

Despite total correction of tetralogy of Fallot being a common cardiac surgical procedure for more than 50 years, [13] some controversy still exists regarding the optimal treatment method [14]. Some groups advocated routine two staged procedure for tetralogy

Table 3: Post-Operative Complications.

\begin{tabular}{|l|c|c|}
\hline \multicolumn{1}{|c|}{ Complications } & Number & Percent \\
\hline Bleeding & 4 & $2.2 \%$ \\
\hline Junctional rhythm & 12 & $6.6 \%$ \\
\hline Complete heart block & 0 & $0 \%$ \\
\hline Re opening & 4 & $2.2 \%$ \\
\hline Acute right heart failure & 6 & $3.3 \%$ \\
\hline Pneumothorax & 2 & $1.1 \%$ \\
\hline Pleural effusion & 11 & 6.15 \\
\hline Respiratory failure & 3 & $1.6 \%$ \\
\hline Seizure & 1 & $0.5 \%$ \\
\hline Acute renal failure & 3 & $1.6 \%$ \\
\hline
\end{tabular}

Citation: Timorian M, Rahman R, Saboor AS (2019) Early Outcomes after Total Correction for Tetralogy of Fallot Patients at Department of Cardiothoracic and Vascular Surgery Amiri Medical Complex Kabul-Afghanistan (A Single Center Study). Clin Res Open Access 5(1): dx.doi. 
of Fallot with a shunt for symptomatic patients during infancy and total correction within 1.5 years of palliation [7]. Other investigators propose selective staged management with initial shunting particularly in patients with less than ideal anatomy [15]. However patients with undergoing staged treatment of tetralogy of Fallot using a palliative shunt and subsequent total correction accrue the risk of two operative procedure and the potential complications of right to left intracardiac shunting, compromised ventricular function and fibrosis with ongoing hypoxemia and myocardial ischemia [16]. The selective operative treatment of tetralogy of Fallot has developed from previous surgical failure and surgical successes with the operative management of various subsets of patients with the tetralogy Fallot [17].

We originally thought that significantly higher operative mortality might be found in those patients with the most severe intracardiac malformation and high hematocrit [18] especially in our center because of luck of experience and poor facilities, despite all problems for the first time we would be able to publish our data and our early postoperative mortality is quite acceptable regarding most experienced centers.

\section{Conclusion}

There is general agreement that the best treatment of patients with tetralogy of Fallot is complete repair in infancy which may reduce the incidence of late electrophysiological and hemodynamic problem and improve survival [19]. The trans atrial approach is a feasible technique for total correction of tetralogy of Fallot patients inadequate pulmonary annulus size according to $\mathrm{Z}$ score with satisfactory echocardiography performance of late postoperative right ventricle and pulmonary valve functions [20]. We evaluated hemodynamics of 26 patients who repaired trans atrial total correction or pulmonary valve reconstructed by pericardial patch they had an excellent function of their reconstructed pulmonary valve with no or mild regurgitation and very good right ventricle function.

\section{References}

1. Lindberg HL, Saatvedt K, Seem E, Hoel T, Birkeland S (2011) Singlecenter 50 years' experience with surgical management of tetralogy of Fallot. Eur J Cardiothorac Surg 40: 538-542.

2. Lee JR, Kim JS, Lim HG, Hwang HY, Kim YJ, et al. (2004) Complete repair of tetralogy of Fallot in infancy. Interact Cardiovasc Thorac Surg 3: $470-474$.

3. Kamel YH, Sewielam M (2009) Arrhythmias as Early Post Operative Complications of Cardiac Surgery in Children at Cairo University. J Med Sci 9: 126-132.

4. Murphy JG, Gersh BJ, Mair DD, Fuster V, McGoon MD, et al. (1993) Long-term outcome in patients undergoing surgical repair of tetralogy of Fallot. N Engl J Med 329: 593-599.

5. Knott-Craig CJ, Elkins RC, Lane MM, Holz J, McCue C, et al. (1998) A 26-year experience with surgical management of tetralogy of Fallot: risk analysis for mortality or late reintervention. Ann Thorac Surg 66: 506-511.
6. Cho JM, Puga FJ, Danielson GK, Dearani JA, Mair DD, et al. (2002) Early and long-term results of the surgical treatment of tetralogy of Fallot with pulmonary atresia, with or without major aortopulmonary collateral arteries. J Thorac Cardiovasc Surg 124: 70-81.

7. Park CS, Lee JR, Lim HG, Kim WH, Kim YJ (2010) The long-term result of total repair for tetralogy of Fallot. Eur J Cardiothorac Surg 38: 311317.

8. Atik FA, Atik E, da Cunha CR, Caneo LF, Assad RS, et al. (2004) Longterm results of correction of tetralogy of Fallot in adulthood. Eur J Cardiothorac Surg 25: 250-255.

9. Dodge-Khatami A, Miller OI, Anderson RH, Gil-Jaurena JM, Goldman AP, et al. (2002) Impact of junctional ectopic tachycardia on postoperative morbidity following repair of congenital heart defects. Eur J Cardiothorac Surg 21: 255-259.

10. Kumar M, Turrentine MW, Rodefeld MD, Bell T, Brown JW (2016) Right Ventricular Outflow Tract Reconstruction with A Polytetrafluoroethylene Monocusp Valve: A 20-Year Experience. Semin Thorac Cardiovasc Surg 28: 463-470.

11. Starr JP (2010) Tetralogy of Fallot: yesterday and today. World J Surg 34: 658-668.

12. Hickey EJ, Veldtman G, Bradley TJ, Gengsakul A, Manlhiot C, et al. (2009) Late risk of outcomes for adults with repaired tetralogy of Fallot from an inception cohort spanning four decades. Eur J Cardiothorac Surg 35: 156-164.

13. Lillehei CW, Varco RL, Cohen M, Warden HE, Gott VL, et al. (1986) The first open heart corrections of tetralogy of Fallot. A 26-31 year follow-up of 106 patients. Ann Surg 204: 490-502.

14. Gatzoulis MA, Balaji S, Webber SA, Siu SC, Hokanson JS, et al. (2000) Risk factors for arrhythmia and sudden cardiac death late after repair of tetralogy of Fallot: a multicentre study. Lancet 356: 975981.

15. Cobanoglu A, Schultz JM (2002) Total correction of tetralogy of Fallot in the first year of life: late results. Ann Thorac Surg 74: 133-138.

16. Yong MS, Yim D, Brizard CP, Robertson T, Bullock A, et al. (2014) Long-term outcomes of patients with absent pulmonary valve syndrome: 38 years of experience. Ann Thorac Surg 97: 1671-1677.

17. Jacobs JP, Jacobs ML, Maruszewski B, Lacour-Gayet FG, Clarke DR, et al. (2005) Current status of the European association for cardiothoracic surgery and the society of thoracic surgeons congenital heart surgery database. Ann Thorac Surg 80: 2278-2283.

18. Hashemzadeh K, Hashemzadeh S (2010) Early and late results of total correction of tetralogy of Fallot. Acta Med Iran 48:117-122.

19. Kim H, Sung SC, Kim SH, Chang YH, Lee HD, et al. (2013) Early and late outcomes of total repair of tetralogy of Fallot: risk factors for late right ventricular dilatation. Interact Cardiovasc Thorac Surg 17: 956-962.

20. Corno AF, Qanadli SD, Sekarski N, Artemisia S, Hurni M, et al. (2004) Bovine valved xenograft in pulmonary position: mediumterm follow-up with excellent hemodynamics and freedom from calcification. Ann Thorac Surg 78: 1382-1388. 